\title{
Characterization and comparative analysis of metallic inclusions in dry, paste and wet ground maize (zea mays) forms and its health implication on humans
}

\author{
T. O. Daniel ${ }^{a, c}$, D. Azaki ${ }^{b}$, C. N. Nwosu ${ }^{c}$, A. O. Olaoye ${ }^{d}$ and G. E. Sule ${ }^{e}$ \\ ${ }^{a}$ Department of Physics/Geology/Geophysics, Alex Ekwueme Federal University Ndufu-Alike, Ikwo, Ebonyi State, Nigeria. \\ ${ }^{b}$ Department of Family Medicine, Federal Medical Centre, Keffi, Nassarawa state, Nigeria. \\ ${ }^{c}$ Department of Materials, School of Natural Sciences, University of Manchester, United Kingdom \\ ${ }^{d}$ Department of Science Laboratory Technology, Federal Polytechnic Offa, Kwara State \\ ${ }^{e}$ Department of Nutrition, Save the Children International, Nigeria. \\ e-mail:danielojonugwathomas@gmail.com; daniel.thomas@funai.edu.ng
}

Received 2 October 2020; accepted 13 November 2020

\begin{abstract}
This study investigates metallic inclusions in ground maize forms of dry, paste and wet using a domestic grinding machine and its health implications to humans. With progressive maize processing using the grinding machine, metals are introduced as contaminants into ground maize due to wear and tear of the grinding discs and other machine parts. Maize samples of $1 \mathrm{~kg}$ each were grinded in wet, paste, and dry forms. The metallic inclusions were extracted from the ground maize forms using magnetization, sedimentation and decantation. The quantity of metallic extractions were quantified using an Electronic weighing balance and the Atomic Absorption Spectrophotometer (AAS) analysis and were characterised using Scanning Electron Microscopy, Optical Emission Microscopy and Energy Dispersive Spectroscopy iron filings were discovered to be the dominant metallic inclusion present in the various food forms and also in the grinding disc with $88.48 \%$ by weight in the grinding disc. The extracted metallic inclusions is $15.7 \mathrm{mg} / \mathrm{kg}, 19.6 \mathrm{mg} / \mathrm{kg}$ and $26.8 \mathrm{mg} / \mathrm{kg}$ for dry, paste and wet ground maize form, respectively. The EDS result confirms iron as the dominant metallic inclusion with trace amounts of silicon and carbon in the ground maize samples. From the SEM analysis of grain size, the dry, paste and wet ground maize had 17, 27 and $36 \mu \mathrm{m}$, respectively. When in excess, the iron filing metallic inclusions from the ground maize accumulates in body organs exceeding the World Health Organisation (WHO) standard limit of $15 \mathrm{mg} / \mathrm{kg}$ since there is no physiological mechanism to eliminate excess iron, thereby leading to health complications. The accumulated iron in the heart causes increased risk of cardiovascular diseases, siderosis and hemochromatosis in the liver leading to hepatoma -the primary cause of cancer of the liver among others-. Elevated levels of free iron also predisposed individuals to high risk of bacterial and viral infections leading to death.
\end{abstract}

Keywords: Maize; metal inclusion; iron filings; scanning electron microscopy; energy dispersive spectroscopy; optical emission spectrometer; health implication.

PACS: 83.80.Ya; 88.10.jn; 68.37.Hk; 83.85.-c; 88.20.df; 94.05.sk; 91.67.Pq

DOI: https://doi.org/10.31349/RevMexFis.67.269

\section{Introduction}

Maize (Corn) also called Zea mays is a cereal known and consumed by humans in most parts of the world. It is the cereal with the highest production rate globally and is also used for livestock feed and fuel [1]. It can be consumed directly (as cooked or roasted corn) or indirectly by further processing alone or alongside other food items as corn meal which bears different names and procedure of making in different parts of the world. As part of its processing, maize can be milled or grinded in dry, paste and wet form depending on the need and meal.

Maize is widely eaten in Northern Italy in a corn meal dish called Polenta and Paste di Meliga (Corn meal cookies) which is corn flour combine with sugar, grated lemon zest, butter and egg yolk after which it is baked in oven for consumption afterwards. It is also largely consumed in subSaharan Africa for meals of different forms. In Nigeria, it is consumed as a bolus meal popularly called "Tuwon Masara" in the northern Nigeria, which can be eaten with different soups. It is made from dry ground maize flour and processed in boiling water. The bolus meal is believed to be highly appetizing, prevents constipation, reduces stomach acidity and risk of diabetes and heart diseases. The wet ground maize is processed into corn pap commonly known as Akamu, Koko, Ogi or Eko in Cameroon and Nigeria. Corn Pap is a corn meal, corn porridge or fermented cereal pudding made from wet ground corn. Traditionally, the grain is soaked in water for up to two days before wet-milling/grinding and sieving to remove husks. The filtered cereal is allowed to ferment for about two days until sour and is subsequently boiled into pap or cooked to make a pudding. Fermented pap is rich in lactobacillus which help prevent sexually transmitted diseases. Pap is also often recommended for people with high blood pressure as it helps to lower blood pressure because of its high potassium and zero sodium content. Maize when compared to other cereals was found to have low glycaemic index which is good diabetics [2]. It replaces lost body fluid due to its high water content. It also increases breast milk secretion for nursing mothers and helps to excrete toxic substances 
in the body through urine. The corn pap is often processed into corn flour jello called "Agidi", corn moulds or Pap Jellos" mostly in West African countries and is used in eating "meat pepper soup". The paste grounded corn is mixed with vegetables wrapped in large leaves popularly called "Uma" and roasted to form "Moilmoil" a popularly corn meal in far northern Nigeria. Maize is found to contain all the essential amino acids needed by the body except tryptophan [3].

Various food processing technologies are employed for commercial, industrial and domestic processing of maize into the different maize meals since cereals are rarely consumed in the raw form. The crop processing varies from one location to another depending on the culture, tradition and technological advancement of a given people. Existing maize processing include milling, cleaning, sieving, grinding and drying among others [4-7 ]. Grinding is a mechanical breaking down or size reduction of food samples into required food form and size using a mechanised mill/grinding machine. A mechanized mill is a fabricated device used in grinding food produce between two revolving abrasive surfaces, usually separated by a predetermined distance and powered by petrol, electricity or diesel. A typical mechanized mill consists of basic metallic components such as the hopper, auger, shaft, grinding disc (crusher) and the prime mover which can easily degrade into grinded food item and introduces metallic inclusions since the grinding discs rub each other during grinding

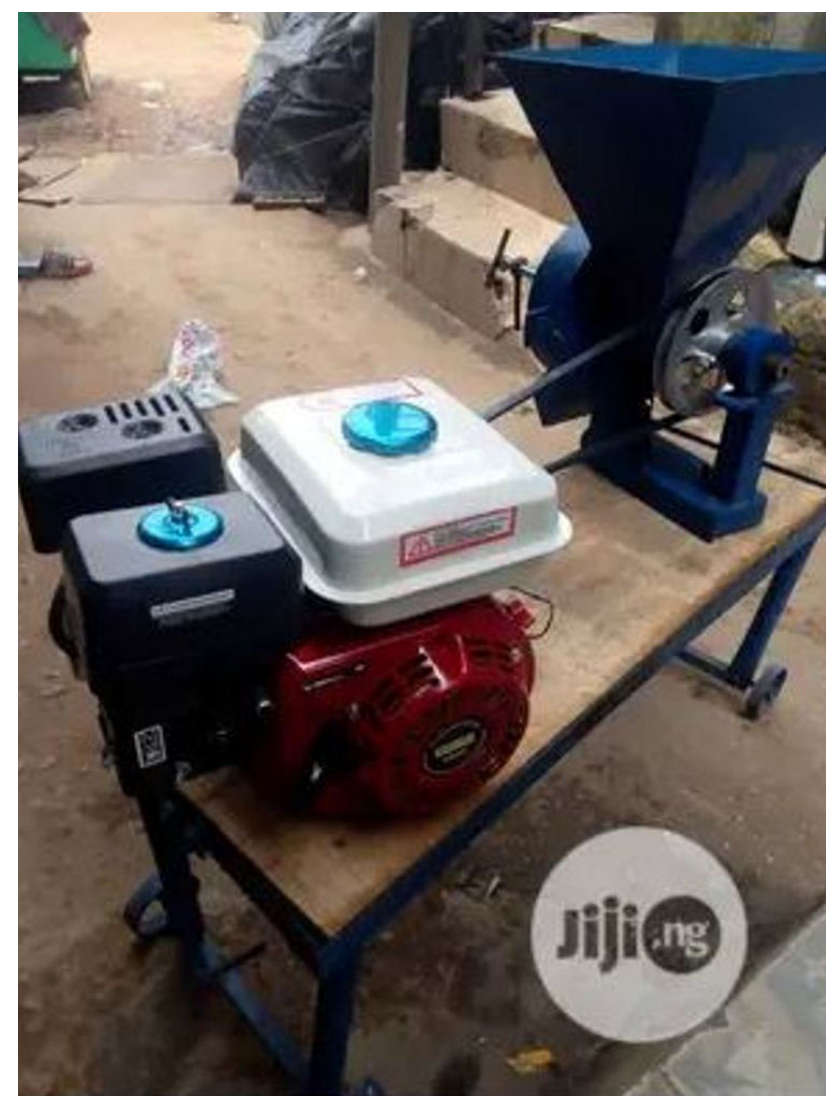

FIGURE 1. A Mechanized mill/Grinding machine (https:// jiji.ng/301-grinding-machines).

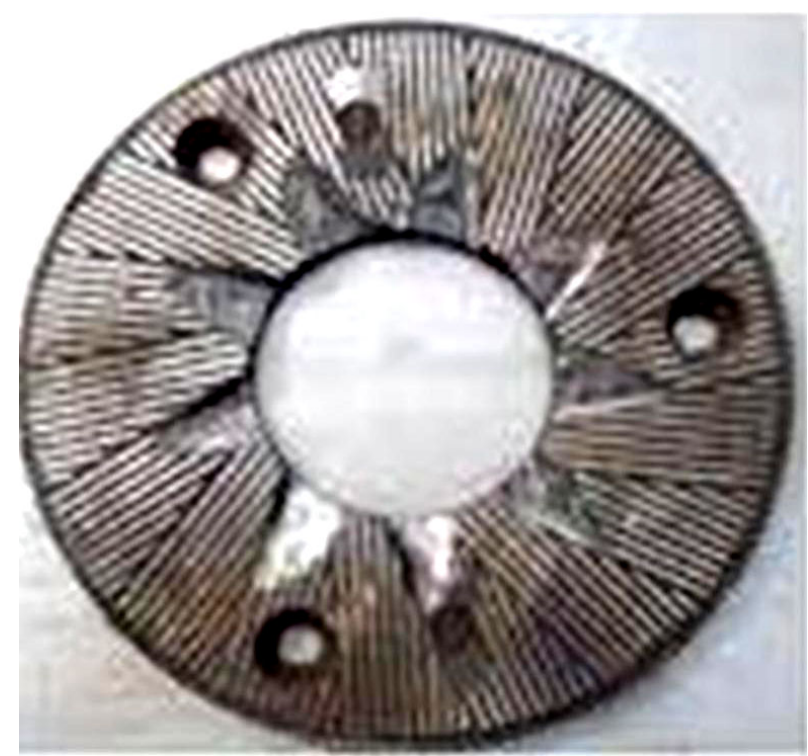

FIGURE 2. A Grinding disc.

of food items [8]. A pictorial view of a typical mechanized mill also called a grinding machine is shown in Fig. 1 while Fig. 2 shows a grinding disc.

The domestic grinding machine makes use of one stationed disc and one rotating disc which are separated by a predetermined distance which define the finest or particle size uniformity of the grinded material. The food item to be grinded are crushed and shared between the two discs. The grinding discs are produced by casting using cast iron scraps. Cast iron is an alloy of iron and carbon in which pig iron is melted in a suitable furnace and modified by the addition of scrap for producing the required shape. Nickel, chromium, silicon, molybdenum, and copper are often added to the cast iron to improve its mechanical properties such as strength, hardness, corrosion resistance and response to heat treatment [8].

The grinding machine is mostly used in sub-Saharan Africa for domestic grinding of maize before maize processing to various corn meal and delicacies. The grinding discs are separated by a predetermined distance for effective application of force/particle size determination for grinding of cereals to a size suitable for human consumption. The size reduction is often classified into two basic divisions depending on solid or liquid as grinding for solid food materials and emulsification for liguid food materials [9-11]. The cereals to be grinded are crushed and sheared between the two discs. Due to the material make-up of the grinding disc it possess poor or no wear resistance, thus necessitating the application of shear force during grinding of food crops via the grinding disc resulting to wearing of discs surface thereby generating metallic inclusions into grinded food. These wear and tear of the machine parts during usage increases with ageing and wearing of the machine bearings, bushings, machine components coating paint among others [11-16] which introduces 
some particles or contamination especially heavy metal inclusions into the ground food.

The contamination of cereals and other food materials which are basic source of human nutrient is of concern to public health $[17,18]$. The metallic inclusions in food are mostly heavy metals which possess a density greater than $5 \mathrm{~g} / \mathrm{cm}^{3}$ such as iron, cadmium, lead, zinc, copper, nickel, cobalt and chromium which could get into the human body upon consumption of the grinded or processed cereals to disrupt normal human body metabolism by limiting and disrupting the operations of the heart, bone, liver, brain, kidney, essential body minerals and nutrients [15-21]. Although, the heavy metals are essential in maintaining physiology and bio chemical functions in living organism when in low concentration, it becomes noxious when ideal concentration threshold is exceeded as the heavy metals cannot be digested by human organs. Toxicity occurs at a level just above the natural occurring background levels of the respective heavy metals so that the consumption of foods with high concentration of a given heavy metal(s) could result to acute poisoning and potential health crisis to human. The presence of metallic inclusions especially iron filings in ground cereals has been reported which could induce hemochromatosis, cancer and death among others $[8,14,16,22]$.

Since maize is a widely consumed cereal which could be grinded in dry, paste and wet form for consumption processing, it is needful to carry out analysis of iron filings inclusion in ground maize samples of dry, wet and paste form, to quantify the presence iron fillings and other metallic inclusions in ground maize and to determine the particle size of the metallic inclusion so as to optimize and recommend the ground maize food form with least iron filling inclusions and the potential health risk associated with metallic inclusions in ground maize. Hence, we report for the first time a comparative analysis of dry, paste and wet ground maize and its health implication on humans.

\section{Materials and methods}

The materials used include maize samples (white maize) which were bought from a local market in Abakaliki, Ebonyi state, Nigeria called Kpirikpiri Market, surgical gloves (Agary pharmaceutical limited, electronic weighing balance (MEDIFIELD Equipment and scientific LTD, MF 500-1108463), stirrer, bar magnet, grinding disc/grinding machine, measuring cylinder, sieve, scanning electron microscopy (SEM), Energy dispersive spectroscopy (EDS) and Optical Emission Spectrometer. The maize samples were sorted out for cleanliness and possible risk to the grinding machine efficiency by picking out stone particles, sand, debris and other possible physical impurities after which $1 \mathrm{~kg}$ each of the dry maize samples were placed in three separate plastic containers labelled Dry, Paste and Wet. The maize samples in the two containers labelled Paste and Wet were soaked in distilled water for thirty (30) hours each with decantation and resoaking of the samples after every six
(6) hours to soften the maize samples and to prepare it for paste and wet form grinding. The three maize samples were grinded with the locknut screwed to exert constant frictional force contact between the grinding discs. However, the paste form was obtained using half ( 0.5$)$ litre of distilled water and while the wet form was obtained using two (2) litres of distilled water at a constant grinding time of 4 minutes each using a pair of close contact but grooved surface grinding discs for the three ground maize forms. The ground samples were weighed, $2 \mathrm{~g}$ each into $250 \mathrm{ml}$ beakers and $10 \mathrm{ml}$ of the acid mixture of $\mathrm{HNO}_{3}$ and $\mathrm{HClO}_{4}(4: 1 \mathrm{v} / \mathrm{v})$ was added. The solution was stirred and heated over a low temperature hot plate in a fume cupboard for 4 hours to achieve complete digestion. The digested samples were allowed to cool, then distilled water was added and the samples filtered into beakers. The filtrate of each sample was transferred into $50 \mathrm{ml}$ volumetric flasks and then made up to mark with deionised water and then transferred into clean sample bottles for Atomic Absorption Spectrophotometer (AAS) analysis. Equal weights ( $2 \mathrm{~g}$ each) of the ground maize samples were weighed on filter papers and a bar magnet was then placed in each of the ground maize samples which were continuously stirred for five (5) minutes each so as to extract iron filings and other possible metallic inclusions using surgical gloves from the ground maize samples by the attraction of the metallic contaminants to the bar magnet. A repeated sedimentation and decantation process was further used to extract the remaining metallic inclusions from the ground maize food samples by mixing each of the ground maize samples with 7.5 litres of distilled water at a constant stirring time of five (5) minutes for each sample to enhance the settlement of the remaining metallic inclusions for extraction until no sediments of metallic inclusions were found. The total extracted metallic inclusions from each sample was measured using an electronic weighing balance. The morphology and the microstructure of the extracted metallic inclusion was characterized using High Resolution Scanning Electron Microscopy (HR-SEM, Zeiss), the elemental composition was determined by an Energy dispersive X-ray spectroscopy (EDS; Oxford instrument) while an Optical Emission Spectrometer was used to determine the chemical composition of the grinding disc sample.

\section{Result and discussion}

\subsection{Chemical composition analysis}

The chemical composition of the grinding disc sample in weight percent as obtained using Optical Emission Spectrometer is shown in Table I while the quantified Iron $(\mathrm{Fe})$ extracted metallic inclusions from each ground maize sample from AAS analysis is shown in Table II. The elemental/chemical composition of the grinding was found to include sulphur, iron, carbon, silicon, nickel, chromium, copper, molybdenum, manganese, phosphorous, niobium and arsenic. Iron was found to be in higher proportion which agree with the report of [6]. Table I shows that the grinding disc 
TABLE I. Chemical composition of the grinding disc sample.

\begin{tabular}{cccc}
\hline S/N & Element & Symbol & Weight $\%$ \\
\hline 1 & Carbon & $\mathrm{C}$ & 3.64 \\
2 & Silicon & $\mathrm{Si}$ & 2.56 \\
3 & Sulphur & $\mathrm{S}$ & 0.01 \\
4 & Manganese & $\mathrm{Mn}$ & 0.31 \\
5 & Chromium & $\mathrm{Cr}$ & 0.76 \\
6 & Copper & $\mathrm{Cu}$ & 1.02 \\
7 & Molybdenum & $\mathrm{Mo}$ & 2.03 \\
8 & Nickel & $\mathrm{Ni}$ & 1.11 \\
9 & Phosphorous & $\mathrm{P}$ & 0.03 \\
10 & Niobium & $\mathrm{Nb}$ & 0.01 \\
11 & Iron & $\mathrm{Fe}$ & 88.48 \\
\hline
\end{tabular}

TABLE II. The weight of the iron fillings and associated metallic inclusions extracted from grinded millet in wet, paste and dry forms respectively.

\begin{tabular}{ccc}
\hline S/N & $\begin{array}{c}\text { Ground maize } \\
\text { sample/form }\end{array}$ & $\begin{array}{c}\text { Weight of Iron } \\
\text { fillings }(\mathrm{mg} / \mathrm{kg})\end{array}$ \\
\hline 1 & Dry & 15.7 \\
2 & Paste & 19.6 \\
3 & Wet & 26.8 \\
\hline
\end{tabular}

sample has 88.48 high percentage of iron. During grinding of the maize samples, shear force is applied causing the grinding disc to rub against each other causing wear and tear of the grinding disc. The wear and tear leads to the iron content of the grinding disc and other trace element present in it to get into the grinded maize sample as iron fillings. Iron is often of necessity in the grinding disc due to durability and strength. The presence of carbon with next highest weight of $3.64 \%$ could be attributed to the cast iron which the grinding disc was made from [23].

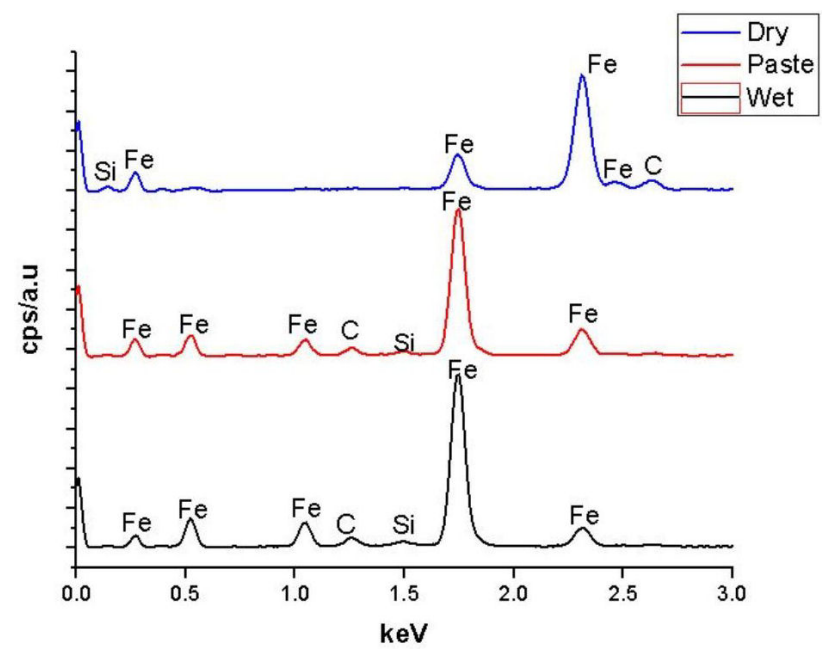

FIGURE 3. EDS spectrum of dry, paste and wet ground maize.
Figure 3 show the EDS spectrum of the extracted metallic inclusion in each sample of the ground maize with the elemental composition distribution of the extracted metallic inclusions as shown. Iron (Fe) filings were also found to be dominant in the grounded maize samples, while small quantities of Silicon ( $\mathrm{Si}$ ) and Carbon (C) were also found since the unalloyed cast iron consist of manganese, carbon, phosphorous, sulphur and silicon composition of traced elements which do not affect the properties of the grinding disc. The presence and quantity of the iron filling inclusion in the ground maize is a function of the elemental composition of the grinding machine's grinding disc. This buttress the composition of the grinding disc, the weight of extracted metallic inclusions and the dominant metallic inclusion as Iron fillings $[5,6]$.

Table II reveals that the wet form of ground maize sample contain the highest quantity of iron fillings and other metallic inclusions followed by the paste and the dry form which has the least quantity of iron fillings and could be attributed to the dry maize serving as a dry lubricant such that it prevents close contact between grinding discs during grinding operation. Negligible results was obtained from the gravimetric analysis carried out using the magnetic bar for the separation of $\mathrm{Fe}$ from the ground samples which could be attributed to the low sensitivity of the bar magnet to pick up Fe fillings in $2 \mathrm{~g}$ samples as compared to the Atomic Absorption Spectrophotometer (AAS).

\subsection{Scanning electron microscopy}

The surface morphology of the dry, paste and wet ground maize extracted metallic inclusion as examined with SEM at a magnification of 1000x is shown in Fig. 4(a-c).

The average particle size of the metallic inclusion in each sample was calculated from the morphology using imageJ software [24,25]. Otsu's thresholding method and particle analysis [25] was used after which statistical analysis of the data was made with a histogram (in Figs. 5, 6 and 7) generated to show the particles distribution. The particle analyser was configured in a size range of $0 \mu \mathrm{m}^{2}$ to infinity in other to allow for coverage of all particles.

Figure 4 shows an increasing trend in the particle size of the extracted metallic illusions from dry $(17 \mu \mathrm{m})$, through paste $(27 \mu \mathrm{m})$ and wet $(36 \mu \mathrm{m})$ forms respectively. From Figs. 5, 6 and 7, the histogram shows a non-uniform Iron filling particle size distribution within the range of 0.0 to $500 \mu \mathrm{m}$ for all the samples. The particle size distribution at 0.0 to $100 \mu \mathrm{m}$ is larger than that of 100 to $1000 \mu \mathrm{m}$ range. A defined particle distribution and pattern exist at $100 \mu \mathrm{m}$ for all the samples. A uniform particle size distribution existed in the dry ground maize sample compared to the paste and wet ground maize form. During grinding of the maize samples, the shear force applied by the machine caused the grinding disc to rub against each other and to possibly cause the wear and tear on the grinding disc which could be responsible for the iron filing and other metallic inclusion extracted from the 


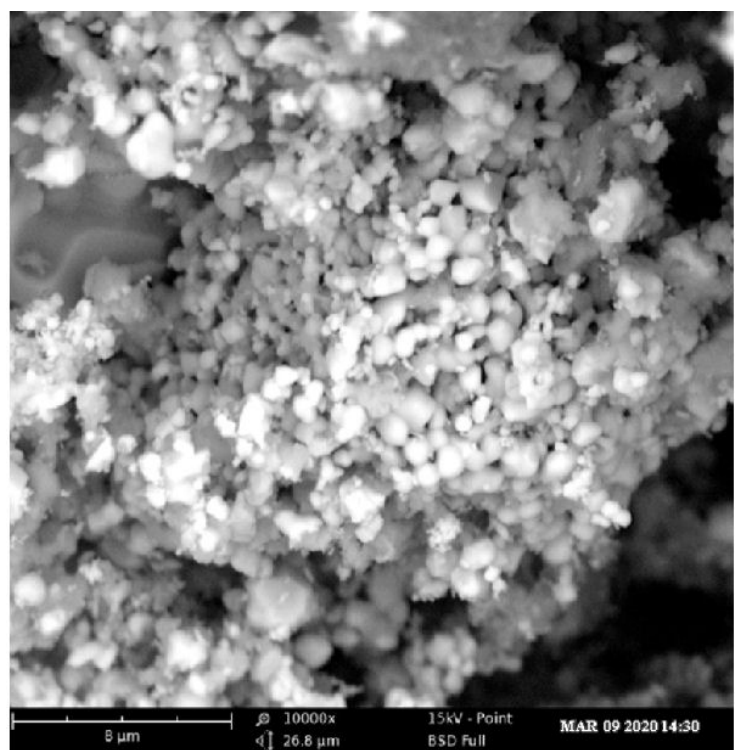

a) Dry

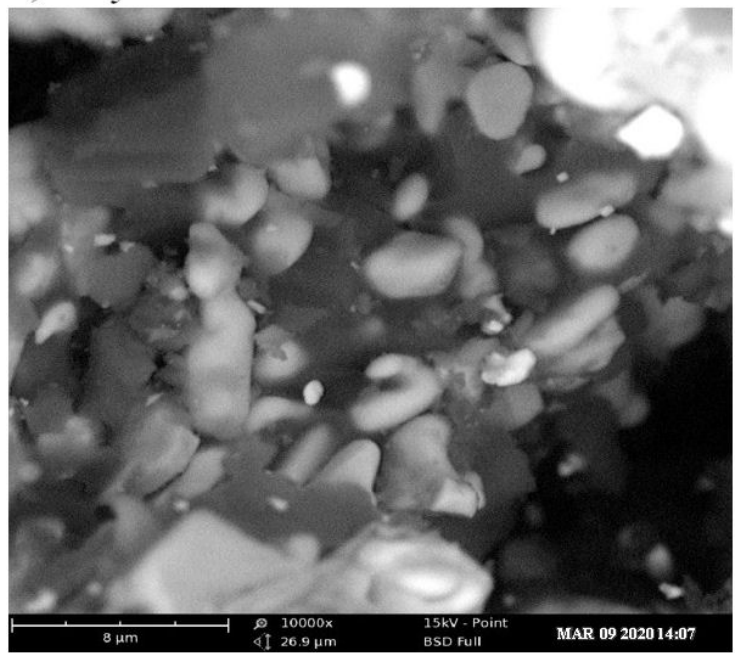

b) Paste

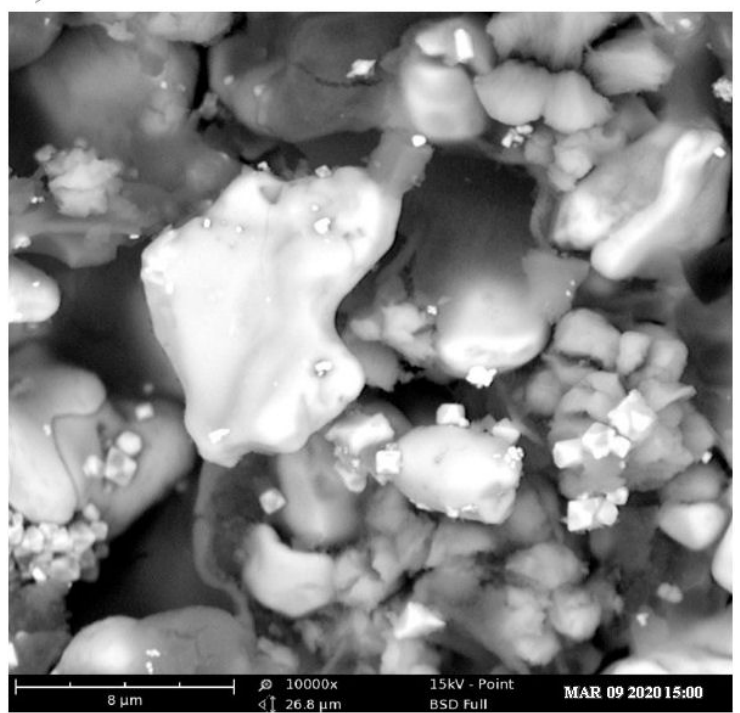

c) Wet

FIGURE 4. The surface morphology of dry, paste and wet ground maize samples.

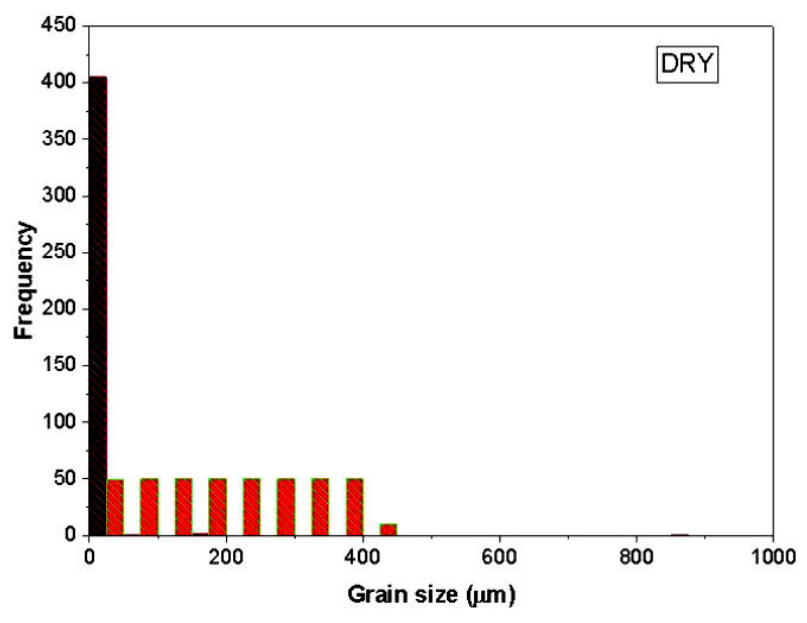

FIGURE 5. Grain size histogram plot for extracted ironic inclusions in from dry ground maize sample

ground maize. The rate of grinding disc material loss during grinding in dry form was slow; this could be attributed to the dry maize sample acting as a dry lubricant, hence preventing close contact between the grinding discs during grinding operation. However, in the wet form and the paste form, the water reduces the friction between the discs such that the grinding speed is higher in the wet form than in the paste form making the wear rate higher in wet ground maize sample than the paste ground maize sample; hence, a reason for the presence of larger amounts of metallic inclusions in the paste and wet form ground maize samples.

\subsection{Health implications of iron filling inclusion}

Iron is the most abundant transition metal in Earth's crust and is biologically the most important nutrient for living creatures as it acts as the cofactor for many vital proteins and enzymes. It is an essential nutrient found in red meat, cereals, etc. Iron mediated reactions enhances respiration in aerobic organisms such that, if not properly shielded, can catalyse the

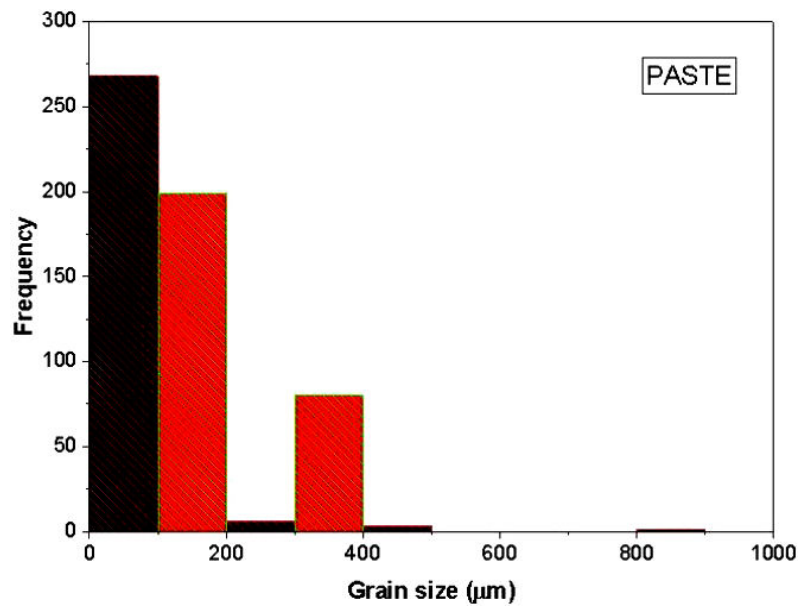

FIGURE 6. Grain size histogram plot for extracted ironic inclusions in from paste ground maize sample. 


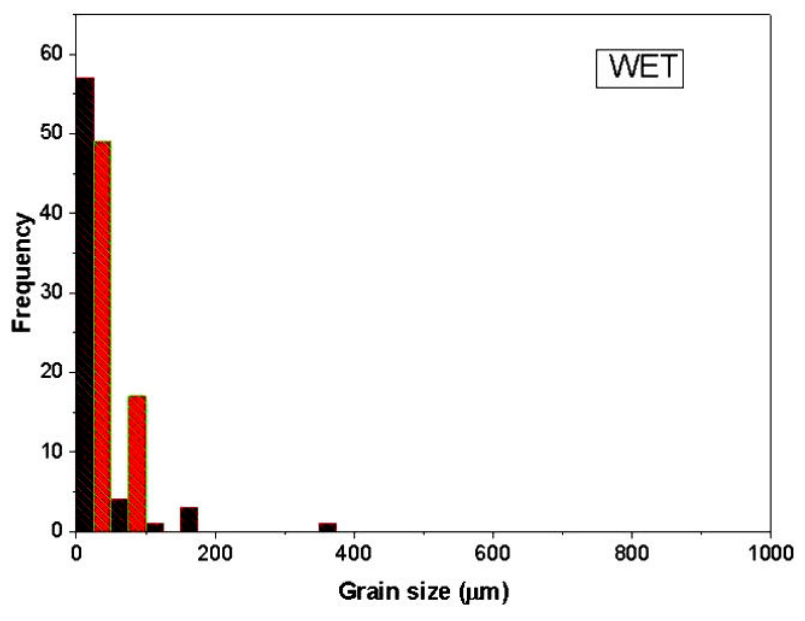

FIGURE 7. Grain size histogram plot for extracted ironic inclusions in from wet ground maize sample.

reactions involving the formation of radicals which can damage body cells, tissues, biomolecules and the entire organism. Iron enhances red blood cell formation as the main component of haemoglobin which aid oxygen transport in human body and brain cell functionality. Many research reports exist on the relevance of iron to the human body system and processes but are focused more on iron deficiency $[21,26]$. Iron deficiency lowers causes iron deficiency anaemia and affects cognition and learning in humans especially in children [27].

The normal iron ideal for the human body system is the mineral iron. However, ingested iron filings get accumulated with time in the human body since they cannot pass through the human organs for digestion [4,14]. The overconsumption, overretention and over-absorption of the iron causes iron overload. The non-mineral iron filing of particle size of $17 \mu \mathrm{m}$ for dry, $27 \mu \mathrm{m}$ for paste and $36 \mu \mathrm{m}$ for wet ground maize is a potential Iron overload to the body system while long term exposure to the iron filings metallic inclusion could result in progressing muscular, cardiovascular, physical and neurological degenerative health conditions [22]. The values obtained exceeded the World Health Organisation (WHO) standard limit of $15 \mathrm{mg} / \mathrm{kg}$ [17]. Excess iron in the body can be measured directly or indirectly. Indirect measurement of serum ferritin levels exceeding 1,500 $\mathrm{ug} / \mathrm{L}$ is diagnostic of iron overload [28]. The iron accumulation or overload causes a disease called hemochromatosis due to the inability of the intestine to keep out unneeded iron; this condition could be acquired or congenital. Congenital hemochromatosis causes the body to absorb and store too much iron especially in the heart, pancreas, body tissue and liver beyond the normal body need and build up in body organs such that if not treated leads to organ damage or failure. A normal human will absorb $1 \mathrm{mg} /$ day but with this disease human system will absorb 3mg/day [13,29]. However, with increased iron uptake from the diet of 1 to $3 \mathrm{mg}$ of iron more than required, in a period of 40 to 50 years, $20-40 \mathrm{~g}$ of iron will be accumulated in the body especially in the liver and heart leading to hepatic diseases and cardiomyopathy.
The accumulation of iron in the liver causes siderosis which when severe could lead to death in young men, impotency in young men and amenorrhea in young women. Iron could accumulate on the pancreas causing necrosis leading to diabetes or on the joints causing arthropathy. The skin is also affected leading to pigmentation. Iron toxicity could also lead to septic shock and inducement of cancer of the liver. Cancer of the liver is caused by the production of reactive oxygen radicals like hydroxyl, superoxide and hydrogen peroxide species which binds nucleic acid base damaging DNA and causing cancers in the long run. Oliguria from diarrhoea and vomiting could lead to acute kidney failure. Other complications include hypothermia, vascular congestion of the gastrointestinal tract, diseases of the thyroid, brain, thymus and adrenals.

\section{Conclusion}

Maize grinded in dry, paste and wet form using domestic grinding machine were investigated and the health implications highlighted. Metallic inclusions were found in the grinded maize. The presence of the metallic inclusions could be attributed to the friction of the grinding discs, misalignment of the grinding disc from the vertical position, wrong and non-uniform sharpening of the grinding discs. Metallic inclusions were released into the ground maize samples due to wearing of the grinding discs, ageing and wearing of other machine components. The metallic inclusion in the ground maize were found to be depended on the ground maize form. The wet ground maize had more metallic inclusions followed by the paste and the dry been the least. Iron filing was found to be the dominant metal inclusion in the ground maize samples. Metal to metal contact in the wet form is higher, but it is difficult for the grinding disc to come in contact with each other in dry form. Results of electronic weight balance measurements, energy dispersive spectroscopy and scanning electron microscopy reveals the presence of more metallic inclusions in maize grinded in wet form than in the paste and dry forms. As such it is recommended that maize should be processed more in the dry form than the paste and wet forms, especially when using the cast iron fabricated grinding machine for human consumption processing of maize. The accumulation of non-mineral Iron occurs due to inability of the human body organs to digest and process it leading to life threating diseases such as Hemochromatosis, cancer of the liver and siderosis among others. It is also recommended that the domestic grinding machine be redesigned with the incorporation of a compartment and a permanent magnet (for magnetization) to minimize or totally eliminate the introduction of iron filings and other metallic inclusions into ground maize and other cereals due to the associated health issues.

\section{Acknowledgments}

The authors acknowledged the Staff and management of Alex Ekwueme Federal University Ndufu Alike Ikwo, Ebonyi state, Nigeria where the laboratory work was carried out. 


\section{Conflict of interest}

The authors declare that they have no conflict of interest.

1. J. A. Gwirtz and M. Nieves Garcia-Casal, Processing maize flour and corn meal food products, Ann. N. Y. Acad. Sci. 1312 (2014) 66, https : //doi.org/10.1111/nyas.12299

2. A. A. Fasanmade and M. M. C. Anyakudo, Glycemic indices of selected Nigerian flour meal products in male type 2 diabetic subjects, Diabetol. Croat. 36 (2007) 33.

3. M. Solomon, R. Aliyu, R. Mohammed, Nutrient composition of foodstuffs and dishes/foods of indigenous population of Jos Plateau, Nigeria, West Afr. J. Food Nutr. 2 (2000) 20.

4. D. B. Yahaya, D. A. Aremu, and I. Abdullahi, Investigation of Metal Contaminants in Locally Ground Foods (Beans and Tomatoes), J. Emerg. Trends Eng. Appl. Sci. 3 (2012) 339.

5. J. K. Odusoste et al., Characterisation of Metallic Contaminants Extracted from Ground Millet, Centrepoint J. 22 (2016) 57.

6. I. A. Kalagbor et al., Estimation of the Levels of $\mathrm{Fe}$ in Wheat and Maize Flour Milled using Commercial Milling Machine and A Home Blender, J. Appl. Sci. Environ. Manag. 21 (2017) 341,https://doi.org/10.4314/jasem.v21i2.15

7. K. L. Mudzingwa and T. Mushiri, Design Of An Automated Millet Milling Machine, in Proceedings of the International Conference on Industrial Engineering and Operations Management, Bangkok, 2019, edited by IEOM (IEOM, Bangkok, 2019), p. 3450.

8. B. O. Anthony, G. C. Chioma, O. L. Oladipupo, and S. O. Titilola, Some Nigerian Traditional Food Milling Techniques and Cookware Increase Concentrations of Some Heavy Metals in Lycopersicon Esculentum and Citrullus Lanatus, IOSR J. Pharm. 3 (2013) 6.

9. P. J. Fellows, Food Processing Technology, 2nd ed. (Woodhead Publishing, Cambridge, 2000).

10. R. L. Earle and M D. Earle, Unit Operations in Food Processing - the Web Edition (The New Zealand Institute of Food Science and Technology, New Zealand, 2004), https://nzifst. org.nz/resources/unitoperations/index.htm

11. O. S. Sule and D. B. Odugbose, Assessment of Dry and Wet Milling using Fabricated Burr Mill, Food Sci. Qual. Manag. 31 (2014) 1 .

12. E. Somers, The Toxic Potential of Trace Metals in Foods. A Review, J. Food Sci. 39 (1973) 215, https : //doi.org/10. $1111 / j .1365-2621.1974 . t b 02860 . x$

13. E. Normanyo, E. K. Esiam, K. Amankwa-Poku, and I. Adetunde, Redesign Of A Grinding Mill For The Minimisation of Iron Filing Production, Researcher 2 (2010) 60.

14. S. Kwofie and H. D. Chandler, Potential health effects of locally-manufactured cornmill grinding plates, J. Sci. Technol. 26 (2006) 137.

15. C. A. Edem and M. I. Dosunmu, Determination of heavy metals in cobs of maize (zea mays) from Calabar south local government area of Cross River State Nigeria, Int. J. Recent Res. Appl. Stud. 13 (2012) 346.
16. J. K. Odusote et al., Assessment of metallic contaminants in grinded millet using domestic grinding machine, Niger. J. Technol. Dev. 14 (2017) 13, https://doi.org/10.4314/ njtd.v14i1.2

17. World Health Organization, Toxicological evaluation of certain food additives and contaminants in food (World Health Organization, Geneva, 2006).

18. A. A. Jigam et al., Determination of copper, zinc, lead and some biochemical parameters in fresh cow milk from different locations in Niger State, Nigeria, Afr. J. Food Sci. 5 (2011) 156.

19. J. M. Llobet et al., Concentrations of Arsenic, Cadmium, Mercury, and Lead in Common Foods and Estimated Daily Intake by Children, Adolescents, Adults, and Seniors of Catalonia, Spain, J. Agric. Food Chem. 51 (2003) 838, https: //doi.org/10.1021/jf020734q

20. G. Wyasu, E. Onoja, F. S. Omeiza, Comparative analysis of the level of lead and cadmium contamination of food during processing with atlas machine and a local grinding stone, Arch. Appl. Sci. Res. 2 (2010) 331.

21. M. Jaishankar et al., Toxicity, mechanism and health effects of some heavy metals, Interdiscip. Toxicol. 7 (2014) 60, https : //doi.org/10.2478/intox-2014-0009

22. I. A. Bello, O. Oke, A. O. Ibrahim, and A. M. AbdulRaheem, Levels of Cadmium, Lead and Zinc introduced as contaminants into foodstuffs during processing, Sci. Focus 12 (2007) 1.

23. A. Ibhadode, Introduction to Manufacturing Technology (AMBIK Publishers, Lagos, 2001).

24. G. Julio, M. D. Merindano, M. Canals, and M. Ralló, Image processing techniques to quantify microprojections on outer corneal epithelial cells, J. Anat. 212 (2008) 879, https: // doi.org/10.1111/j.1469-7580.2008.00898.x

25. T. Daniel, U. Uno, K. Isah, and U. Ahmadu, Electric Double Layer Field Effect Transistor Using SnS Thin Film as Semiconductor Channel Layer and Honey Gate Dielectric, East Eur. J. Phys. 3 (2019) 71, https: / / doi.org/10.26565/ 2312-4334-2019-3-09.

26. D. Lee, Hereditary Hemochromatosis, 2009, https : //www . medicinenet.com/iron_overload/article.htm

27. L. Hulthén, Iron deficiency and cognition, Scand. J. Nutr. 47 (2003) 152, https://doi.org/10.1080/ 11026480310005720

28. Y. Kohgo et al., Body iron metabolism and pathophysiology of iron overload, Int. J. Hematol. 88 (2008) 7, https://doi. org/10.1007/s12185-008-0120-5

29. Canadian Hemochromatosis Society, Normal Iron Absorption and Storage in Iron Filings, The Newsletter of the Canadian Hemochromatosis Society, 2005, https://www.toomuchiron.ca/wp-content/ uploads/2013/11/2005_spring.pdf 